\title{
Therapeutic validity of pimpinella annisum on iraippu noei (bronchial asthma)
}

\begin{abstract}
Iraippu noi is one of the Kapha rogam in Siddha Medicine comparable to Bronchial Asthma in Allopathic medicine. There is a tightening and pain in the chest without an apparent cause. In addition difficulty in expiration it sounds resamples the musical sound of kulal, yarl, Veenai. Anise is an aromatic herb, it's botanically belongs to the Umbelliferae family of the genus Pimpinella and known scientifically as Pimpinella anisum. This is the quasi experimental study conducted in OPD/IPD of Ayurveda Rural Hospital, Kopalapuram, and Trincomalee. Fifty (50) patients diagnosed as Iraippu noi (which bear a resemblance to Bronchial Asthma in Allopathic medicine) were enrolled for this study to estimate the effectiveness of the Peruncheraha powder, a single herbal Siddha formulation on Iraippu noi. It also observed the side effects of Peruncheraha powder and determine the association of Iraippu noi with the seasonal variation, food, habit and hereditary. $2 \mathrm{gm}$ of Peruncheeraha Churanam was administered internally twice a day before meals with hot water, used sugar as an adjuvant for a period of 40days.

The effect of the treatment was assessed based on subjective and objective parameters with seven intervention treatment arms. The results were assessed in terms of clinical recovery, symptomatic relief and pulmonary function improvement. Finally, Paired' test was used to test the significance of data received from the clinical assessments, such as Breath holding time, Respiratory Rate, and Peak Flow Rate. At the end of the treatment (40th day) $77.7 \%$ patients had "Marked improvement" and 22.2\% had "Moderate improvement". Based on the results patients were found extremely significant symptomatic improvement by clinically and there was a significant reduction in all symptoms in end of the study. It provides the successful proof of the traditional literature about Peruncheeraham.
\end{abstract}

In general it is hoped that the findings of this study would help in the global use of Peruncheeraha powder for the treatment of Iraippu noi.

Keywords: iraippu noi, peruncheeraham, pimpinella anisum
Volume 12 Issue 5 - 2019

\author{
Paheerathan V \\ Senior Lecturer, Unit of Siddha Medicine, Eastern University of \\ Sri Lanka, Sri Lanka
}

Correspondence: Paheerathan V,Trincomalee Campus, Eastern
University of Sri Lanka, Sri Lanka,Tel 0772347677, Email geethan1978@live.com

Received: May 24, 2019 | Published: Ocober II, 2019

\section{Introduction}

\section{Study}

This is the quasi experimental study to determine the internal administration of Peruncheeraha powder in the management of Iraippu noi. Bronchial Asthma is a very common disease ${ }^{1}$ of the human respiratory system ${ }^{2}$ and it's a major health problem (WHO, 2014). This is well-known hypersensitivity disorder which prevalence is being rapidly intensified in present world particularly in developed countries. $^{3}$

The prevalence of Bronchial Asthma has increased significantly since the 1970s. About 300 million people worldwide have asthma and by 2025 it has been estimated that a further 100 million will be affected In India, it is estimated that 57,000 deaths were attributed to Bronchial Asthma in 2004 (WHO, 2004). And it was seen as one of the leading cause of morbidity and mortality in rural India (In 2009 Bronchial asthma caused 250,000 deaths globally). ${ }^{1}$

The Siddha text book scripts denote more plants for the therapeutic usages of bronchial asthma. Among them the Peruncheerakam is one of the plants that have the character \& therapeutic value to cure Bronchial asthma efficiently. But the (powder) form of this seeds for Iraippu noi is state on theoretical view only, no one has evaluated yet.
There still many drugs which are a part of this system either been kept hidden. The current study will be carried out to proof the statement scientifically \& want to identify the safe\& cost effective drug to help to cure \& control the disease (Bronchial Asthma) without or mild side effects. Hence this study is evaluated by the clinical knowledge and experience. This study helps to standardize the Peruncheeraka powder as treatment of Iraippu noi for global use. The fundamental constituents that constitute living body \& its total physiological aspects are considered as Vata, Pitta\& Kapha (collectively referred as Dosha) and imbalance to their existing proportion is responsible for provoking any disease according to Siddha Medicine. So disease is regarded as just state of Dosha imbalance. The disease then can manifest variably as symptoms, according to etiology \& pathogenesis it follows. Thus two major considerations of illness origin are the dosha imbalance \& specific pathogenesis they follow which results into specific symptom manifestation. ${ }^{4}$ On the other hand, factors produce dosha imbalance is diminution of those factors that balance dosha homeostatically. The factors which give way to specific pathogenesis followed by dosha is individual specificity depend on genetic makeup, widely known as Prakruti. $^{4}$

The features of Bronchial Asthma are quite comparable with the disease "Tamak-swasa" described in Ayurveda. In fact swasa is a major clinical condition according to Ayurveda that includes classes 
\& sub-classes in it, carries symptomscan closely resembles with chronic obstructive pulmonary disease situation. Ayurveda describes etiology \&pathogenesis of all classes of swasa including tamakswasa (Bronchial Asthma) almost similar with just little difference. However, the treatment modalities described are specific with class to class $\&$ sub-class. ${ }^{4}$

\section{Iraippu noi}

Iraippu noi is one of the kapharogam in Siddha comparable to Bronchial Asthma in Allopathic medicine. Iraippu noi is one of the 21 types of Iya noi. In Siddha system of medicine the disease Swasakasam (Bronchial Asthma) is characterized by sever cough with or without expectoration, expiration is like a hiss of a serpent, frequent hemming and sense of heat in both nostrils, hoarseness of voice, indigestion and flatulence. ${ }^{1}$ The causes of the disease as per Siddha text are exposed to excessive smoke, excessive intake of cold water and food items, increased acidity, excessive intake of non-vegetarian diet, lack of exercise, intake of allergy inducing food, starving on hunger, taking improperly cooked food and excessive mental stress. ${ }^{5-9}$

\section{Peruncheeraha chooranam}

Pimpinella anisum belongs to Umbelliferae family, has been widely used as an indigenous medicine for the treatment of indigestion for many years. However, the bronchodilator property of P. anisum has been proved experimentally. Therefore, the present study will be undertaken to identify the effectiveness of internal administration of P. anisum powder in the management of Bronchial Asthma. The seeds of $\mathrm{P}$. anisum are a scientific based, side effect less herbal medicine for Bronchial Asthma. Based on literature citation the following researches was done this plant So far, different studies were performed on aniseeds and various properties such as antimicrobial, antifungal, antiviral, antioxidant, muscle relaxant, analgesic and anticonvulsant activity as well as different effects on gastrointestinal system have been reported of aniseeds. (Research findings of other ingredients are mentioned in Literature Review).

It can also reduce morphine dependence and has beneficial effects on dysmenorrhea and menopausal hot flashes in women. In diabetic patients, aniseeds showed hypoglycemic and hypolipidemic effect and reduce lipid peroxidation. ${ }^{5}$

\section{Objective of the study}

To determine the effectiveness of P. annisum on Iraippunoi

\section{Methodology}

This is the quasi experimental study, Irraipu noi patients, according to the inclusive criteria, were selected at the Siddha Rural Hospital, Kopalapuram, Trincomalee. The selected patients were treated with selected drug.

The selected drug was administered for forty days with seven intervention treatment arms.

\section{Study area}

The study area was the Trincomalee in the eastern province of Sri Lanka. Kopalapuram Ayurvedic Rural Hospital was selected for this study.

\section{Study unit}

50 patients were selected based on Randomization schedule.

\section{Study duration}

The study was conducted from February 2015 to July 2015.

\section{Selection of Iraippu noi patients}

According to the inclusive criteria patients were selected for the study from Out Patient Department and ward of Rural Hospital, Kopalapuram. The purpose of trial was explained to the patients, get their consent. All selected patients were interviewed by the researcher on their first visit to the OPD. The patients were subjected to a detailed clinical examination based on proforma specially prepared for this study. Diagnosis was made on the basis of history and clinical examination. After subjective \& objective investigations the patient without any complications were only included in this study.

The following physical examination was made by the researcher;

a. Addavitha patidchai (villi, molli, navu, naddi, malam, siruner, sparisam, niram)

b. Blood Pressure, Pulse, Temperature and Respiratory rate.

c. In systemic examination special emphasis was given to the Respiratory System. In addition to this Cardiovascular System was also examined by the researcher.

Fifty patients were selected, these patients were selected within the study frame (February 2015-June 2015) using inclusion/exclusion criteria based on the sign and symptoms of Iraippu noi in the first phase of screening procedure. The purpose of the trial was explained to the patients those who volunteered signed informed consent to enroll in the trial. (The Informed consent form was shown in annexure 3).

\section{Inclusion criteria}

a. Patients of either gender belonging to the over 15 to below 65 year's age group.

b. The patients who were suffered from bronchial asthma

c. Diagnosis of disease based on typical history with these cardinal symptoms

i. Productive cough

ii. Difficulty in breathing

iii. Wheezing

\section{Exclusion criteria}

1. Patients having age below 15 years and above 65 years with acute attack, ie, status asthmatic stage

2.Patients suffering structural lung disease like Tuberculosis, Carcinoma of respiratory tract, smokers' bronchitis, pneumonia, Co-pulmonale, cardiac asthma.

3. Other systemic disorder like diabetic mellitus, hepatitis, and sexually transmitted disease

4. Those with evidence of severe unstable renal, hepatic, hemopoietic, nervous and cardiac disorder as revealed by history and/or investigations.

5. Women who were pregnant, lactating, and having child bearing potential.

6. Patients with known contra indication to any of the investigational 
products and medicinal plants.

7. Those with history of having received any investigational drug in the previous one month.

8. Those unwilling to come for regular follow-up for the entire duration of the study and any patients considered not eligible according to the investigator's discretion.

\section{Withdrawals}

Patients could withdraw voluntarily or at the discretion of the researcher. Patients were not replaced and the new patients who were enrolled the next consecutive number. Efforts were made in each case to identify the reason for a failed follow-up visit and/or withdrawal.

\section{Treatment}

\section{Internal medicine}

To all the patients, this plan drug was administered in the dose of $2 \mathrm{~g}$, twice a day with warm water. It can be given with sugar as an adjuvant.

\section{Adverse effects}

Patients were specifically questioned as per a predetermined list of common symptoms as drowsiness, fever, flatulence, vomiting, nausea, and headache, prolong sleep time, heart burn, burning sensation, tremor, based on researcher's experiences in clinical practice and mentioned in literatures. Patients were also encouraged to volunteer information that they considered to be adverse events (AE) or a side effect (SE). The researcher recorded opinions on the causality/ relevance of $\mathrm{AE} / \mathrm{SE}$ in each case.

\section{Clinical evaluation}

All the selected cases were carefully examined and records were maintained. To arrive at the diagnosis along with the history taking, physical examinations and some investigations were done.

The investigations were as follows: Pulmonary function tests:

(a) Breathe holding time - measured by stop watch.

(b) Peak expiratory flow rate measured with help of Peak flow meter.

\section{Result and interpretation}

Overall effect of therapy on each scale was calculated with reference to percentage improvement in all symptoms, each patient was assessed on the basis of signs and symptoms of the disease. The clinical efficacy of the drug was analyzed statistically on all the symptoms mentioned in the assessment criteria. Initially, the variation and significance of effect seen within the 09 patients were calculated by paired $t$ test. The difference of individual score SD was calculated with Standard Error in Mean (SEM). These data are shown as Mean \pm SEM. Then, to more specifically quantify the percentage of improvement in each patient, this was also calculated using the formula $(\mathrm{BT}-\mathrm{AT}) \times 100 / \mathrm{BT}$. On the basis of grading pattern as well as percentage relief, patient were classified under the five categories. Such as complete remission, markedly improvement, moderately improvement, mild improvement and poor response.

Effect of therapy is evaluated as
1. $<25 \%$ - Poor response/unchanged

2. 26-50 \% - Mild improvement

$3.51-75 \%$ - Moderate improvement

4. 76-99\% - Marked improvement

$5.100 \%$ - Complete remission.

\section{Instrument}

The instrument used in this study is an interviewer (researcher) administrated questionnaire. In addition to responses to specific questions, notes were made on information obtained by examination and investigations. The follow-up of the patients were recorded at $3^{\text {rd }}$, $6^{\text {th }}, 14$ th, 21 th, 28th, 35th, 40th, day intervals these questions were prepared based on specific objectives.

\section{Data analysis}

The data was analyzed using the Statistical Package for Social Sciences (SPSS) version16.

\section{Result and comments}

\section{Effect of drug on cough}

All selected patients were showed cough (Figure 1). The initial mean value of cough was 2.56 and it was reduced as 0.78 on $21^{\text {st }}$ day of treatment at the $40^{\text {th }}$ day it was 0.11 .There were significant mean differences among the before and after treatment $\left(21^{\text {st }}\right.$ day and $40^{\text {th }}$ day). All of them got improvement of cough at the end of the treatment. The study showed statistically highly significant improvement of "p" value $(p<0.001)$. It clearly denotes that the drugs were effective on cough.

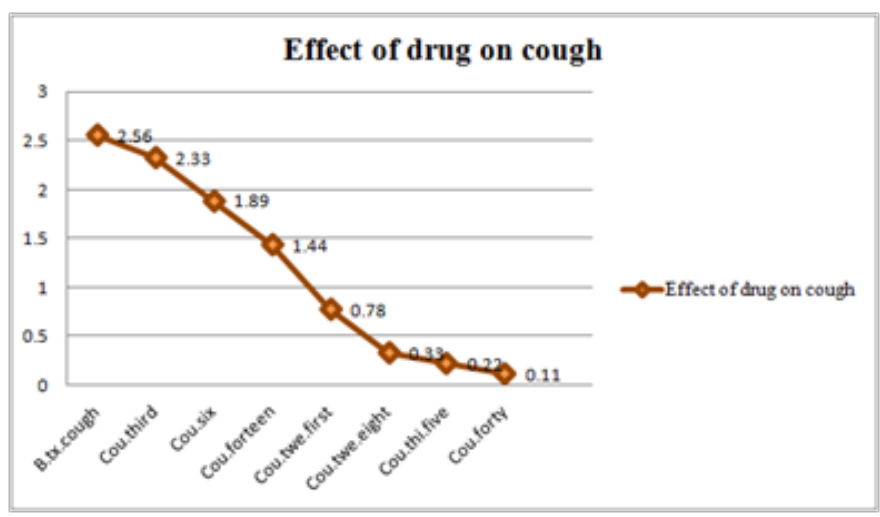

Figure I Effect of drug on cough.

\section{Efeect of drug on Dyspnoea}

All selected patients were showed dyspnea (Figure 2). The initial Mean value of dyspnea before treatment was 2.78. Mean after treatment on $21 \mathrm{st}$ and $40^{\text {th }}$ day were reduced as 1.11 and 1.0 respectively. There were significant mean differences among the before treatment and after treatment $\left(21^{\text {st }}\right.$ day and $40^{\text {th }}$ day). All of them got improvement of dyspnea at the end of the treatment. But they can be got this condition, when doing more than custom works. The study showed statistically highly significant improvement of "p" value $(p<0.001)$. It clearly showed that the drug was effective on dyspnea. 


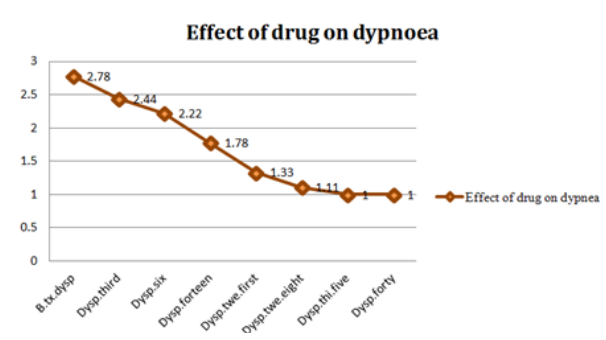

Figure 2 Effect of drug on dyspnoea.

\section{Efeect of drug on wheezing}

All selected patients were showed Wheezing (Figure 3). The initial Mean score before treatment was 2.22. The Mean score was reduced after treatment on $21 \mathrm{st}$ and $40^{\text {th }}$ day as 1.0 and 0.22 respectively. There were significant mean differences among the before treatment and after treatment ( $21^{\text {st }}$ day and $40^{\text {th }}$ day). Most of them got improvement of wheezing at the end of the treatment. Although very few numbers of patients had wheezing at the end of the treatment. But they can be getting this condition, when doing more than custom works and exposure of hyper responsive stimuli. The study showed statically highly significant improvement of " $p$ " value $(p<0.001)$. It was found in the study that the medicine has therapeutic effect on wheezing.

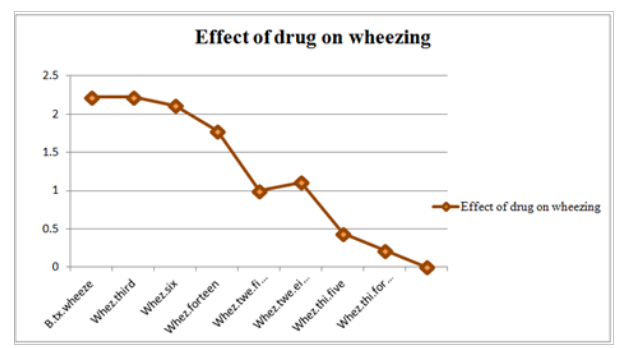

Figure 3 Improvement of Wheezing after the treatment.

\section{Effect of drug on breath holding time}

All selected patients were showed various breaths holding time which was in fewer amounts than normal (Figure 4). The initial Mean score was 2.67. The Mean score was improved after treatment on $21^{\text {st }}$ and $40^{\text {th }}$ day as 4.3 and 5.22 respectively. There were significant mean differences among the before treatment and after treatment $\left(21^{\text {st }}\right.$ day and $40^{\text {th }}$ day). All of them got improvement of breath holding time at the end of the treatment. The study showed statically highly significant improvement of " $p$ " value $(p<0.001)$. It clearly denoted that the drug was effective to increase the breath holding time.

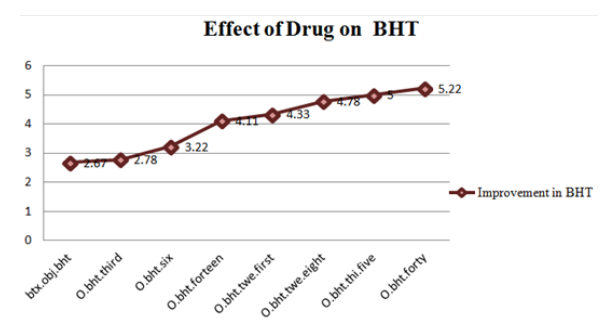

Figure 4 Effect of drug on Breath holding time.

\section{Effect of drug on respiratory rate}

All selected patients were showed increased respiratory rate than normal range. The initial Mean score was 5.67. The Mean score was reduced after treatment on $21^{\text {st }}$ and $40^{\text {th }}$ day as 4 and 3.33 respectively. There were significant mean differences among the before treatment and after treatment $\left(21^{\text {st }}\right.$ day and $40^{\text {th }}$ day). Most of them got reduction of respiratory rate in normal range, at the end of the treatment. Fewer showed reduction of respiratory rate but not the normal range. The study showed statically highly significant improvement of "p" value $(p<0.001)$. It clearly denoted that the drug was effective to increase the breath holding time (Figure 5 ).

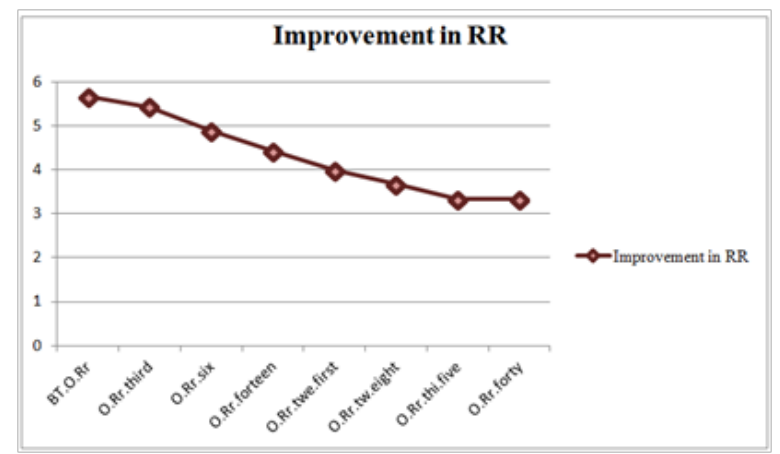

Figure 5 Effect of drug on Respiratory Rate.

\section{Effect of drug on peak flow rate}

All selected patients had problem with performed peak flow rate for the normal range. $11.1 \%$ patient could not perform the peak flow rate at the first visit. $88.8 \%$ patients were done correctly. The initial mean value of peak flow rate 4.00 and it increased as 5.44 on $21^{\text {st }}$ day of treatment. At the $40^{\text {th }}$ day it was 6.33 . There were significant mean differences among the before treatment and after treatment $\left(21^{\text {st }}\right.$ day and $40^{\text {th }}$ day). All of them got improve on the peak flow rate at the end of the treatment. The study showed Stastically highly significant improvement of "p" value $(p<0.001)$ (Figure 6). It clearly denotes that the drug was effective on increase of peak flow rate.

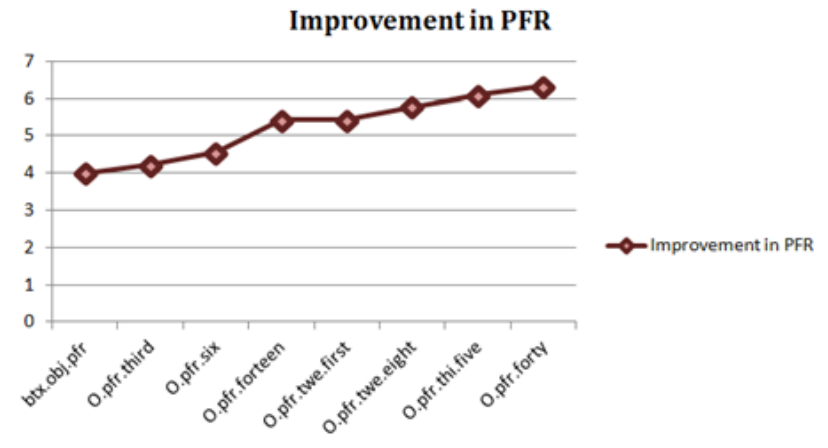

Figure 6 Effect of drug on Peak flow rate.

\section{Overall effect of drug in the improvement of symptoms}

The mean of all symptoms were showed that cough before treatment was 2.56 (more than 6 times per a day) and after treatments were 0.11 (No cough). Percentage of relief was $95.70 \%$. Mean of Dyspnea before treatment was 2.78 (on less than accustomed work) after treatment was 1 (on more than accustomed work). Percentage of relief was $64.03 \%$. Mean of Wheezing before treatment was 2.22 (During night time) after treatment was 0.22 (No wheezing). Percentage of relief was $90.10 \%$.here cough and wheezing relieved by all patients, but dyspnea can be developed due to the excess manual work, i.e., more than accustomed works (Table 1). 


\section{Overall effect on drug in improvement of signs}

The mean of signs Table 2 shows BHT before treatment was 2.67 (16-18) Sec. After treatment it was 5.22 (22-24) Sec. Percentage of reliefs were $95.50 \%$. Mean of RR before treatment was. 5.67 (25-27) $\mathrm{b} / \mathrm{min}$ after treatment was $3.33(16-18) \mathrm{b} / \mathrm{min}$. Percentage of relief was $70.27 \%$. Mean of PFR before treatment was 4.00 (140-190) 1/ min after treatment was 6.33(250-290) 1/min Percentage of relief was $58.25 \%$. Most of the patients got improvement in breath holding time approximately more than half of them got reduction of increase respiratory Rate. But the Peak flow rate was not showed marked improvement.

Table I Overall effect on drug in improvement of symptoms

\begin{tabular}{lllll}
\hline No & $\begin{array}{l}\text { Subjective } \\
\text { parameters }\end{array}$ & Mean before treatment & Mean after treatment & $\begin{array}{l}\text { Percentage of } \\
\text { relief }\end{array}$ \\
\hline I & Cough & 2.56 (more than 6 times per a day) & 0.1 I(No cough) & $95.70 \%$ \\
2 & Dyspnea & 2.78 (on less than accustomed work) & I (on more than accustomed work) & $64.03 \%$ \\
3 & Wheezing & 2.22 (Durin night time) & 0.22 (No wheezing) & $90.10 \%$
\end{tabular}

Table 2 overall effects on drug in improvement of each signs

\begin{tabular}{lllll}
\hline No & $\begin{array}{l}\text { Objective } \\
\text { parameters }\end{array}$ & Present before treatment & Present after treatment & $\begin{array}{c}\text { Percentage of } \\
\text { relief }\end{array}$ \\
\hline I & BHT & $2.67(16-18) \mathrm{Sec}$ & $5.22(22-24) \mathrm{Sec}$ & $95.50 \%$ \\
2 & RR & $5.67(25-27) \mathrm{b} / \mathrm{min}$ & $3.33(16-18) \mathrm{b} / \mathrm{min}$ & $70.27 \%$ \\
3 & PFR & $4.00(140-190) \mathrm{l} / \mathrm{min}$ & $6.33(250-290) \mathrm{l} / \mathrm{min}$ & $58.25 \%$
\end{tabular}

\section{Overall therapeutic effect of treatment}

Figure 7 showed, overall effect of treatment on the $21^{\text {st }}$ and $40^{\text {th }}$ day in $21^{\text {st }}$ day $44.4 \%$ had mild improvement, $33.3 \%$ had moderate improvement, and $22.2 \%$ had marked improvement. At the end of the treatment ( $40^{\text {th }}$ day) $77.7 \%$ had come under "marked improvement" and $22.2 \%$ fell under "moderate improvement".

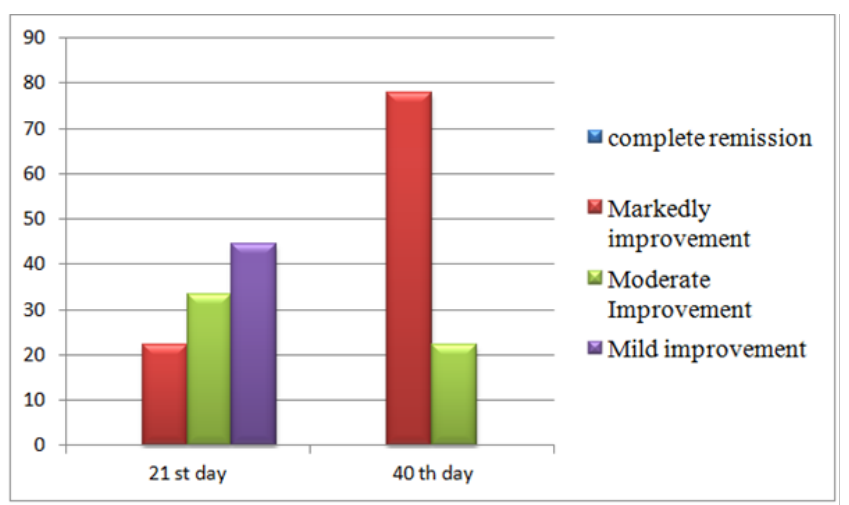

Figure 7 Overall Therapeutic effect of treatment.

Explanations for the effectiveness of the trial drug on Iraippu noi with Siddha pharmacodainamics Effectiveness is explained on the basis of Rasa, Veeriya, Vipaka, action and properties of Váta and Kapha.

Iraippu noi is one of the Kapha rogam which may cause derangement kapham. Iya kuttram. Kapham is the basic reason to cause it. Also association of kapham with vatham may be a lead to the severity of this disease. Hence to treat Iraippu noi drugs acting on both
Vata and Kapha should be selected and it has the light and penetrating properties with hot potency.

The gunas of the Ilaghu and tikshna (light and penetrating properties) and Ushna veeriyam (hot potency) drug are antagonistic to the gunas of kapha dosa, thereby normalizing kapha dosa. Quality to normalize or suppress the vata dosha (vitiated vata dosa) and amasaya (upper part of stomach), which is seat of kapha want to prescribe ushna veriya (hot potency) drugs.

i. Sour, Salt and Pungent have hot potency.

ii. Sweet, Astringent and Bitter have cold potency.

However, the Siddha text book denotes that the sweet, sour and solt taste pacify vatha dosha and pungent, astringent and bitter taste pacify Kapha dosha respectively.

Therefore the above mentioned taste as well as hot potency (Ushna veeriyam) drugs can be prescribed for the treatment of Iraippu noi. The selected single herbal preparation (Peruncheeraham chooranam) Pimpenella anisum has the Suvai of pungent and sweet, Veeriyam is hot, Vipaakam is pungent, Dosha samanam is Vatha iyam.

Pungent shows predominance of fire and air elements, \& qualities like hot, dry and light nature. It pacifies Kapha. It improves circulations and clears the channels. It has an anti-spasmodic action. Same as it has the quality of warms body and promotes sweating, improves metabolism and relieves nerve pain. Mentally it gives opens mind and senses, when it increases it leads irritability, anger, impatience. The Sweet taste has the quality nourishes, builds and strengthens body tissues and mentally gives soothing, calming, satisfactory, when it is excess intake leads mentally gives lethargy, anxiety. Anise seeds have expectorant action also the main composition is Trans-anethole, it 
has medicinal importance because of its carminative and expectorant effect. The volatile oil which has a beneficial action on the bronchial tubes, and for respiratory disease. If administered in hot water, is an immediate palliative.

On the overall, Peruncheeraha churanam has significant effect on (Iraippu noi). Above explanations has been supported by the results obtained from this study.

\section{Conclusion}

The present study was conducted to estimate the Effectiveness of Peruncheeraka churanam types of Bronchial Asthma and define their risk with age, gender, occupation, dietary habit, phisical activity, seasonal variations, family history, and atopic dermatitis, pets in home, smoking \& alcoholic habit. Clinical trial usually focuses on asthma control as measured by pulmonary function test (PEFR, Breath holding time and Respiratory rate) .symptom scores and medication requirement. The results were assessed in terms of clinical recovery, symptomatic relief and pulmonary function improvement. The effect of the treatment was assessed based on subjective and objective parameters. The results demonstrate that the formulation can be used as an effective drug in Bronchial asthma however detailed observational studies are required to demonstrate the effect of drug at molecular level.

On the basis of results and the findings of this study, the following conclusion can be arrived at;

1.Peruncheeraha churanam can be used as a highly effective internal administration for Iraippu noi and no serious side effect was detected.

2. It provides the successful proof of the traditional literature about Peruncheeraham.

3. In general it is hoped that the findings of this study would help in the use of Peruncheeraha powder for the treatment of Iraippu noi.

\section{Acknowledgments}

None.

\section{Conflicts of interest}

Author declares there are no conflicts of interest.

\section{References}

1. Banu G. Nalinisofia H, Vetha Merlin Kumari H. et al. Pre-clinical and clinical study on Swasakasam (Bronchial Asthma) and the drug of choice is thuthuvalayathy chooranam. Int J Pharm Bio Sci. 2014;4(2):102-108.

2. Shanmugavelu M. Noinaadal Noimuthal Naadal Thirattu. Part II, $8^{\text {th }}$ edn Chennai: Inthiya Maruththuvam Homeopathythurai; 2010. p. 135-148.

3. Madhavi PVD, Vishal P. Asthma Therapy in Ayurveda: An Ancient Scientific Approach. Pharmageme. 2013:1(1):57-64.

4. Sharma R, Dash B. Charaka Samhit. Varanasi, India: Chukhambha Sanskrit Series Office; 2001.

5. Asie S, Mehri A. Review of Pharmacological Properties and Chemical Constituents of Pimpinellaanisum. ISRN Pharm. 2012;2012:510795.

6. World health organization (WHO). Media center, Fact sheets N 307 Asthma. Geneva: World health organization; 2013.

7. World health organization (WHO). The Use of Traditional Medicine in Primary Health Care: A Manual for Health Workers in South-East Asia: New Delhi: WHO Regional office for south - East Asia. Geneva: World health organization; 1990.

8. WHO: Bronchialasthma, Factsheet ${ }^{\circ},-$ Asthma. Geneva: World health organization; 2006.

9. World health organization (WHO). Media center, Fact sheets N 307 Asthma. Geneva: World health organization; 2013. 